\title{
Effects of Expansion of Cultivation on Pastoralism as a Food-Security Measure in Longido District, Northern Tanzania
}

\author{
Victoria Anthony Nderumaki ${ }^{1,}$, Francis Xavier Mkanda ${ }^{2}$, Josephat Alexander Saria ${ }^{1}$ \\ ${ }^{1}$ Department of Environmental Studies, Faculty of Science, Technology and Environmental Studies, The Open University of Tanzania, Dar- \\ es-Salaam, Tanzania \\ ${ }^{2} \mathrm{C} / \mathrm{O}$ George Nxumalo, Department of National Parks and Wildlife, Mzuzu, Malawi
}

Email address:

vickynde@yahoo.com (V. A. Nderumaki)

${ }^{*}$ Corresponding author

\section{To cite this article:}

Victoria Anthony Nderumaki, Francis Xavier Mkanda, Josephat Alexander Saria. Effects of Expansion of Cultivation on Pastoralism as a Food-Security Measure in Longido District, Northern Tanzania. International Journal of Environmental Monitoring and Analysis. Vol. 5, No. 6, 2017, pp. 159-166. doi: 10.11648/j.ijema.20170506.12

Received: September 17, 2017; Accepted: October 4, 2017; Published: December 11, 2017

\begin{abstract}
The pace at which cultivation is expanding in the pastoral livelihood zones accentuates the need to take a proactive role in choosing land use practices that increase food production in areas such as Longido District where climate variability renders agricultural production uncertain, but pastoralism as the mainstay of the economy. This study used a structured questionnaire to randomly assess the perceived impact of expansion of cultivation on 165 respondents in three ecological zones, namely Lowlands, Hills, and Mountains of Longido District in Northern Tanzania. Results show that expansion of cultivation results into reduced herd-splitting, a practice that enhances niche specialization grazing land by browsers and grazers. It also leads to loss of grazing land, restricted livestock movement, and escalation of conflicts between pastoralists and farmers. Considering the role pastoralism in the district, these effects are a potential threat to pasture availability, livestock productivity, and food security. To minimize the threat, it would be appropriate for the Longido District authorities, in conjunction with the communities, to establish reserves of grazing lands based on ecological zones. Such areas would have to be protected by traditional rules, coupled with village by laws that shall be strictly enforced as part of a foodsecurity policy.
\end{abstract}

Keywords: Expansion of Cultivation, Grazing Land, Food Insecurity, Pastoralism, Ecological Zones

\section{Introduction}

This study provides justification for discouraging cultivation, within pastoral zones so as to promote pastoralism, which is the proper socio-economic activity in semi-arid areas $[1,2,3]$ such as Longido District. In fact, pastoralism is considered a means of ensuring food security in such areas. There is no added advantage in cultivating such areas because yields of main crops in the District, e.g., maize and beans are extremely low [4, 5]. For instance, maize and bean yield in the Lowland ecological zone of Longido, where pastoralism is the main stay, averages 76.3 and $134.7 \mathrm{kgha}^{-1}$ respectively instead of 2000 and $1200 \mathrm{kgha}^{-1}$ as is the case on arable (suitable for cultivation) land for the whole of the Arusha Region, where Longido is located. The differences in the yields are more likely a result of climatic conditions, not poor agronomic practices $[4,6]$.

The low yields contribute to food insecurity, which is rampant in the area. As an adaptation to the food insecurity, communities expand cultivation as a strategy to increase crop yield [7, 8]. According to the Longido District Council's office responsible for Livestock and Agriculture, the area of land cultivated rose from 1688 to 13326ha, an increase of about 689\% between 2011 and 2014. Invariably, this expansion involved conversion of grazing land into cultivated fields [9]. This increase in the amount of cultivated land is not surprising considering that during the same period, the number of households involved in cultivation rose 
by almost $71 \%$, i.e., from 8,960 to 15,300 .

At the time when cultivation is increasing, there is a concomitant increase in the population of livestock. For example, according to the same office responsible for Livestock and Agriculture in Longido, cattle increased from 88,630 in 2011 to 210,267 in 2015 , goats 211,362 to 397,013 and sheep $(96,236-284,161)$ during the same period. This increase is attributed to Government efforts to promote pastoral production through introduction of improved breeds of cattle, sheep, and goats besides improving awareness of the availability of veterinary extension services. This livestock population growth implies that there is a need for adequate grazing land. The expansion of cultivation into grazing land, therefore, will undoubtedly frustrate the Government's efforts to promote pastoral production. That is more the reason for protecting grazing land from cultivation in Longido.

The increase in livestock population in Longido District, while there is expansion of cultivation, calls for a long-term strategy to ensure that pastoralism is not unnecessarily displaced. Such a strategy, however, can better be formulated if the effects of expansion of cultivation on pastoralism are properly understood. This study, therefore, intended to determine the effects with a view to identifying means of protecting the semi-arid land in Longido against further cultivation.

\section{Methodology}

The choice of Longido as a study site has an advantage over other areas because the district is new, and hence in the process of preparing development plans. This being the case, it is an ideal site to observe the effects of expansion of cultivation on pastoralism because the results can be incorporated into the development plans for the district so as to avoid diminishing the food security offered by pastoralism.

\subsection{Description of the Study Area}

A previous study gives a full description of the study site [4]. It suffices, therefore, to only mention that Longido District (Figure 1) lies south of the equator between latitudes $2^{\circ} 20^{\prime}$ and $3^{\circ} 10^{\prime}$ South, and between longitudes $36^{\circ} 00^{\prime}$ and $37^{\circ} 3^{\prime}$ East of Greenwich. It was formed after the government divided Monduli District into two (Monduli and Longido). It borders the slopes of the Mount Kilimanjaro and hills of Longido, Ketumbeine, Gelai, and Oldonyo Lengai. The altitude ranges from $300 \mathrm{~m}$ for the low elevation to $2,900 \mathrm{~m}$ at high elevations. This diversity of topography results into 3 ecological zones, i.e., Lowlands, Hills, and Mountains lying between 300 and 600, 600 and 900, and 900 and 1200 meters above sea level respectively.

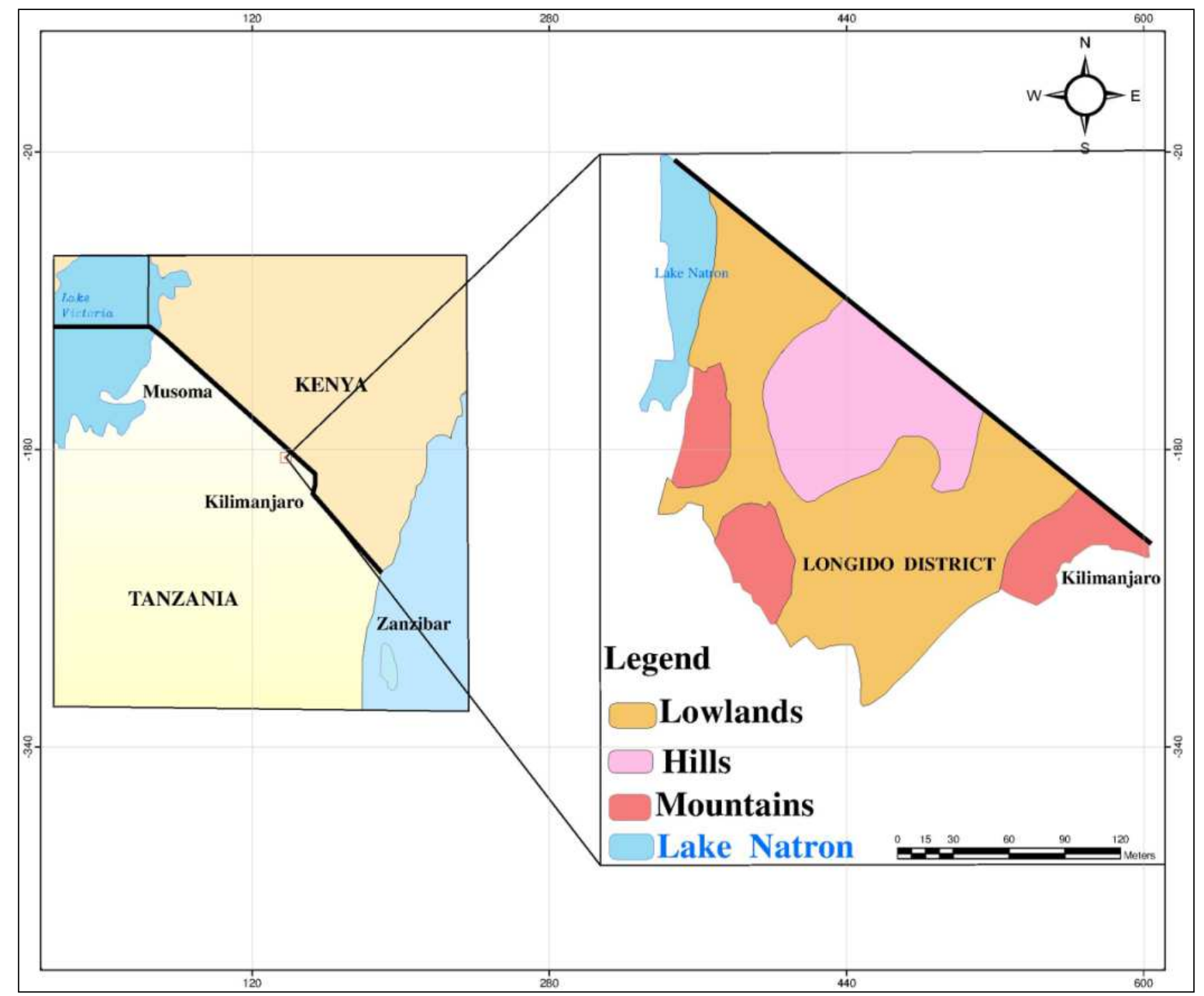

Figure 1. Sampling Strata in Longido District, Northern Tanzania. 
The district has a total area of $7,782 \mathrm{~km}^{2}$ of land, out of which $6,392.35 \mathrm{~km}^{2}$ (about $82 \%$ ) is grazing land, $365.78 \mathrm{~km}^{2}$ forest reserve, and $731.64 \mathrm{~km}^{2}$ arable land according to the Longido District Council responsible for Agriculture and Livestock. The local community is predominantly Maasai, a tribe which lives as a clan in a structure called boma that typically consists of 7 households with an average of 6 family members each. The Masaai are predominantly cattle owners, which emphasizes the importance of pastoralism as a means of food security in the district.

\subsection{Data Collection}

To assess the effects of expansion of cultivation on grazing land, primary data were collected following the methods used in the previous study [4], i.e., stratifying the study area into three strata based on its ecological zones, namely Lowlands, Hills, and Mountains, and using a structured questionnaire. The questionnaire was designed taking content, wording, and format into consideration, as recommended by Parfitt [10]. A questionnaire survey was preferred over other techniques, for example the Rapid Rural Appraisal (RRA), and Participatory Rural Appraisal (PRA), because it is considered to be more appropriate for such studies [10]. The structured questions were useful on issues where a specific range of known responses was expected. Such questions allow easier interpretation and analysis than open-ended ones [11] or PRA and RRA.

The stratified random sampling method was used to collect data by interviewing 165 respondents. This sample size was determined from 27,367 households in the whole district of Longido [12]. The sample size was determined using the Sample Size Calculator by the Creative Research System; the sample size being calculated at a Confidence Level of 99\%, and $10 \%$ Confidence Interval. The total sample size of 165 was divided by 3 (number of strata) to come up with an equal number of 55 respondents for each stratum. The strata were based on the ecological zones, i.e., the Mountains, Hills, and Lowlands. If it were practical, a sample size for each stratum would have been derived separately because the population sizes may not be equally distributed in each ecological zone. However, that would only be practicable if the population census data had been presented on the basis of ecological zones. To the contrary, population data are based on administrative boundaries of wards or villages, which do not match with those of ecological zones. Superimposing village or ward boundaries on ecological zones, therefore, would have been reduced to mere guess work. To avoid such a risk, the total sample size was simply divided by 3 (number of strata) to come up with an equal number of 55 respondents for each stratum. The formula used to calculate sample size is as follows:

$$
\mathrm{Ss}=\frac{\mathrm{Z} 2 *(\mathrm{p}) *(1-\mathrm{p})}{\mathrm{c} 2}
$$

where

Ss is the sample size
$Z$ represents the $Z$ value (e.g., 1.96 for $95 \%$ confidence level)

p percentage picking a choice, expressed as decimal $(0.5$ used for sample size)

c represents the confidence interval, expressed as decimal (e.g., $0.04= \pm 4$ )

The questionnaires were administered in Swahili, the lingua franca of Tanzania. Prior to the survey, a pilot study of 20 respondents was undertaken to check a number of questionnaire design aspects, such as clarity, appropriateness of the questions, and respondents' willingness to participate in the survey. An informed consent form was signed by each respondent as evidence that they were neither induced nor coerced to participate in the survey.

\subsection{Data Analysis}

Out of 165 questionnaires, only 144 (87\%) were analysed because the rest were from respondents that acted suspiciously, hence their responses were considered unreliable. It is believed that the exclusion of the questionnaires from suspicious respondents did not influence the final results because the difference between the calculated and achieved sample sizes is minor. Where appropriate, statistical tests were done in order to determine if differences in response probabilities were statistically different between the respondent categories or strata. All tests were conducted in the JMPIN Starter Statistics software version 3.2.1 [13].

\subsubsection{Respondents' Profiles}

Before determining the effects of expansion of cultivation, it was important to create profiles of the respondents so as to have an insight into the demography and socio-economics of the communities in the pastoral livelihood zone of Longido. To construct the profiles of the respondents, variables such as size of household, age, level of education, main socioeconomic activities, household income, cultivated land size, type and number of livestock owned, and residential status were used. These characteristics were chosen because they were most pertinent in having an insight into the composition of the communities in Longido.

Household sizes were arbitrarily grouped as 2-5, 6-9, 1015 , and $>16$, but age categories followed the Life Cycle Grouping method used by Statistics Canada, i.e., children=014 years of age, youths $=15-24$, adults $=25-65$, and seniors $=>65$. The level of education attained by the respondents was classified as not at all $=$ no education, primary=grades $1-7, \quad$ secondary=forms $1-6, \quad$ and tertiary $=$ colleges and universities. Main socio-economic activities were used as per their known categories, i.e., farming=growing crops, pastoralism=those predominantly grazing livestock, agro-pastoralism $=\mathrm{a}$ combination of farming and pastoralism, and other=petty trading and employment. Household income was calculated in millions of Tanzanian Shillings (TZS) ${ }^{1}$ per annum and categorized as

1 US\$1.00 was about TZS 2244.00 in September 2017 
$<0.10,0.11-0.50,0.51-1.0$, and 1.1-5.0. Cultivated land size was categorized as $0.5-5.0,5.1-10.0,10.1-15.0$, and $>15.1$ ha. The residential status was defined as settled=not nomadic or semi-nomadic, and not settled=nomadic. For each variable, sums of the number of respondents by category and stratum were calculated.

\subsubsection{Perceived Effects of Expansion of Cultivation}

Perceived effects of cultivation were analyzed based on the most common range management practices in Longido, e.g., herd-splitting, fencing of grazing land known as Olopololi, and livestock movement. Herd-splitting involves separating young from mature animals, but also grazers from browsers, for instance cattle being herded separately from sheep and goats. Olopololi involves use of Acacia thorns to fence off grazing land so as to avoid it from use during the rainy season; it is open to livestock during dry season. This is a traditional practice that allows grasses and shrubs to regenerate when the area is used by either browsers or grazers respectively thereby increasing niche specialization while reducing impact on land, which would otherwise lead to land degradation [14].

The responses were grouped and summed up by stratum. Analysis focussed on what respondents selected from arrange of responses perceived to be the effects of expansion of cultivation on pastoralism. The Correspondence Analysis test was used to determine the degree of association between the responses and strata. This test is similar to the Chi-square, but more useful for data with many levels [15] in this case 3 strata, and different types of responses.

\subsubsection{Association Between Perceptions of Impact of Expansion of Cultivation and Respondents' Characteristics}

Other studies have shown that personal characteristics influence perceptions, peoples' attitudes and practices [16, 17, 18, 19]. Such being the case, this study intended to identify characteristics of the respondents that influenced their perceived effects of expanded cultivation. Again, the number of respondents possessing these characteristics was summed up by stratum and the perceived effect of expansion of cultivation. The Correspondence Analysis test was again used to determine the degree of association between the characteristics of the respondents and perceived effects of expanded cultivation.

\section{Results and Discussion}

This section provides an interpretation of the results arising from the quantitative assessment of the respondents' views on the expansion of cultivated land. Specifically, it provides explanations for the perceived effects of expansion of cultivation on pastoralism, and the characteristics of the respondents that influenced such perceptions.

\subsection{Respondents Profiles}

The profiles of the respondents suggests that the decision to settle in a particular location is not random, neither was it made by immature or ignorant individuals, but rather mature, knowledgeable persons with some education (table 3). A majority $(84.7 \%)$ of the respondents are settled or considered semi-nomadic. They comprised mostly adults and seniors (about 60 and 35\% respectively), which is not surprising considering that in the Maasai culture, only men or heads of families are allowed to talk in any gathering [20]. The respondents have attained formal education, at least up to primary school level; only $36.8 \%$ do not have any formal education. Just like elsewhere in Tanzania, the main economic activities in the different ecological zones include agriculture, which is dominantly practiced in mountainous areas because of good rainfall and soils while pastoralism, agro-pastoralism, are prevalent in the Lowlands and Hills respectively. Most of the respondents cultivate between 0.5 and 5.0ha of land, especially in the Mountains.

Considering that apart from agriculture or pastoralism, some respondents indulge in more than one economic activity, e.g., employment or petty trading, there are multiple responses (202) with regard to sources of income (table 3). The highest earning respondents (TZS1.1-5.0 million) are in the Lowlands, where pastoralism is the mainstay, not cultivation. That this stratum is cultivated at all irrespective of the small number of respondents, therefore, is counterproductive to generation of substantive income. That highest earnings are in the Lowlands is not surprising considering that livestock has higher returns than crops such as beans and maize. For example the price of beef is TZS $7,700.00 \mathrm{~kg}^{-1}$ while maize and beans fetch TZS 600.00 and TZS $1400.00 \mathrm{~kg}^{-1}$ respectively [21].

\subsection{Perceived Effects of Expansion of Cultivation}

There are 5 effects of expansion of cultivation in Longido (Table 1). Considering the importance of pastoralism in the district, it is not surprising that the Lowlands is the stratum where the impacts are most perceived. The Correspondence Analysis revealed that there is a very high significant association between the strata and perceived effects of expansion of cultivation $\left(X^{2}=53.6, \mathrm{p}=<0.0001\right)$. For example the Mountains are highly associated with escalated conflicts between pastoralists and farmers, restricted movement of livestock, and reduced herd-splitting, while the Lowlands are very much linked with loss of grazing land, an increase of the practice of fencing off pasture, and food insecurity. The Hills, on the other hand, are greatly related with food insecurity, and also increase of the practice of fencing off pasture. 
Table 1. Perceived Effects of Expansion of Cultivation on Pastoralism in Longido District, Northern Tanzania.

\begin{tabular}{|c|c|c|c|c|c|}
\hline \multirow{2}{*}{ Effects } & \multicolumn{3}{|c|}{ No. of responses by stratum } & \multirow{2}{*}{ Total } & \multirow{2}{*}{$\%$} \\
\hline & Lowlands & Hills & Mountains & & \\
\hline Loss of the practice of herd-splitting & 46 & 32 & 40 & 118 & 26.6 \\
\hline Loss of grazing land & 40 & 28 & 14 & 82 & 18.5 \\
\hline Increase in the practice of fencing & 35 & 36 & 7 & 78 & 17.5 \\
\hline Restricted livestock movement & 19 & 27 & 25 & 71 & 16.0 \\
\hline Food insecurity & 25 & 30 & 9 & 64 & 14.4 \\
\hline Escalated conflicts & 16 & 2 & 13 & 31 & 7.0 \\
\hline Total & 181 & 155 & 108 & 444 & 100.0 \\
\hline
\end{tabular}

Although main economic activities are predominant in a particular stratum, it does not imply that the rest are absent where one is dominant. This explains why there is an escalation of conflicts between pastoral communities and farmers in the Mountains (Table 1) a stratum highly associated with farming. The conflicts occur because of various reasons. Fences made from branches of Acacia trees are used to protect the cultivated land to control crop damage by domestic or wild animals. Another source of conflict is the inherent nomadic and semi-nomadic nature of pastoralism. Herders' sometimes tend to traverse cultivated land as they move their livestock seasonally in search of pasture [19]. Furthermore, where agriculture is dominant and cultivated land is protected by fences, livestock movement is restricted, a thing that goes against traditional practices in the Maasai Steppe, where Longido is located [22]. From time immemorial, livestock movement is considered key to management of grazing land in the Maasai Steppe. Escalation of conflicts implies that pastoralists can no longer freely access grazing land [23], especially now that movement of livestock is blocked by fences. Such a scenario is likely to affect the nutritional condition of livestock, and food security subsequently.

As regards herd-splitting, as more land comes under cultivation, herd-splitting can no longer be practiced. Instead, more households mix grazers and browsers in individual grazing areas. Consequently, there is no longer niche specialization as livestock are forced to graze irrespective of the quality of the pasture. The other consequence is the likelihood of land degradation due to over-grazing, which could negatively impact both the farmers and pastoralists. It is common knowledge that once the land is degraded, it becomes unproductive. It can no longer support either farming or pastoralism.

That loss of grazing land and increase of the practice of fencing off pasture are highly associated with the Lowlands, where pastoralism is the main economic activity, is hardly surprising. The mere fact that land is being opened for cultivation obviously means it will not be available to pastoralism. With respect to fencing in this zone, its main purpose is completely different from in the Mountains. The practice, locally known as Olopololi, is used as an adaptive management tool to secure pasture from being utilized by intruders. Paradoxically, the expansion of cultivation fuels the practice of fencing individual grazing land, which leads to the collapse of the 'common grazing land' concept which is key in pastoralism within the Maasai Steppe.
It must be mentioned that while Olopololi is seen as beneficial to individuals, it is, however, being discouraged by government authorities because it contributes to the neglect of the communal grazing land there by making it susceptible to degradation considering that individuals pay more attention to their Olopololi than the former. Contrary to the Government's reason for discouraging the practice, other authors contend that pastoralists are less likely to have emotional ties with the communal grazing land because they are not the defacto owners, and hence cannot be expected to be committed to conservation of the soil and pasture, a phenomenon conventionally known as tragedy of the commons [24]. In contrast, fencing brings a sense of ownership and commitment to conserving the land.

The significant association between the Lowlands and food insecurity in this instance is reflective of the low crop yields of maize and beans, which are the major source of food in all the three strata [4]. Low crop yield and loss of grazing resource invariably contributes to food insecurity because climatic conditions in these strata are not as suitable for cultivation as in the Mountains. Poor crop selection, particularly the growing of maize and beans as a main crop in such an environment exacerbates household vulnerability to food insecurity. In semi-arid areas such as Longido, crops of choice be the ones that are tolerant to such climate, e.g., millet, sorghum, cassava, sweet potatoes, etc. Being the stratum with the highest number of livestock, one would expect that the communities sell or barter livestock with grain and other farm products to ensure food security. However, that it is not always the case because pastoralists have the notoriety of being rigid; they do not easily to sell or barter their cattle. Such rigidity needs changing by means of extension and awareness campaigns, otherwise endeavours to reduce food insecurity through development of pastoralism may be in vain.

The Hills are also linked with fencing practices, and food insecurity for the same reasons as those for the Mountains and Lowlands respectively. There is need to emphasize that food insecurity is the most enduring effect of expansion of cultivation into grazing land. Given the threats posed by the effect of expansion of cultivation on pastoralism, there is a possibility that its role as a source of livelihood would diminish because selling of livestock may not even be a coping strategy given the rigidity of pastoralists. To minimize the threat in the long-term, the strategy should be to strictly enforce the existing village land-use plans. Such enforcement will require formulation of by laws that support food 
security. Although it is a requirement by the Government of Tanzania that villages be governed by bylaws, just like municipalities and district councils, some gaps still exist. For example, Longido has by laws on forests reserves, but none with respect to the implementation of village land-use plans for food production. Without such bylaws, pastoralism stands to lose in the wake of expansion of cultivation and its associated effects. This study also recommends that in collaboration with communities, it would be proper if the Longido District authorities were to establish reserves of grazing areas based on ecological zones as a means of promoting the development of pastoralism and environmental conservation. The reserves would be governed by traditional rules, coupled by village bylaws that should be strictly enforced as part of a food-security policy.

\subsection{Association Between Perceptions of Impact of Expansion of Cultivation and Respondents' Characteristics}

According to the Correspondence Analysis test, age, cultivated farm size, and education are the factors that influenced the perceptions of the respondents with respect to the effects of expansion of cultivation (Table 2). Age is a factor because older persons are more likely to own cattle and hence perceive the effects of expanded cultivation than young ones. With respect to education, people with some formal education tend to be more aware of issues within their environs than those without it $[16,17,18]$. With regard to cultivated farm size, the larger the farm the higher the likelihood of conflicting with livestock grazing.

Table 2. Respondents' Characteristics Associated with Perceptions of Impact of Expansion of Cultivation, Longido District, Northern Tanzania.

\begin{tabular}{lll}
\hline Respondent characteristic & $\boldsymbol{X}^{\mathbf{2}}$ & $\mathbf{P}$ \\
\hline Age & 130.9 & $<0.0001$ \\
Cultivated land size & 79.4 & $<0.0001$ \\
Education & 31.3 & 0.0080 \\
Household income & 6.78 & 0.96 \\
Household size & 15.4 & 0.43 \\
Livestock type and number & 2.9 & 0.98 \\
Residential status & 3.9 & 0.57 \\
Socio-economic activity & 13.5 & 0.19 \\
\hline
\end{tabular}

The implication is that the strata where respondents are more elderly, cultivate larger areas of land, and have attained higher levels of education are more likely to perceive the effects of expansion of cultivation than in the other strata. In this case all strata have more or less the same number of adults and seniors as well as respondents with formal education. In terms of cultivating large pieces of land, however, the Mountains has more respondents than the other strata. This association between perceptions and respondents' characteristics merely underpins the one between perceptions and strata. These results are further justification for establishment of reserves of grazing lands.

\section{Conclusions}

This study set out to provide justification for discouraging expansion of cultivation so as to support pasture management, a key to development of pastoralism in semiarid areas. As such, it has demonstrated that the expansion of cultivation in Longido affects pastoralism in various ways, e.g., loss of grazing land, loss of communal grazing practices, and loss of herding practice such as herd splitting and long distance livestock movement. Cumulatively, these effects result into food insecurity.

\section{Recommendations}

To minimize the threat, the long-term strategy should strictly enforce the existing village land-use plans. Such enforcement will require formulation of bylaws that support food security. It would be appropriate for the Longido District authorities to collaborate with communities to establish reserves of grazing lands based on ecological zones. Such grazing lands would be better protected by traditional rules, coupled by village by laws that are strictly enforced as part of a food-security policy.

\section{Acknowledgements}

The authors would like to sincerely acknowledge the support of the local community who spared their time responding to the questionnaires and taking the principal and first co-author around the remote pastoral areas. Acknowledgements also go to the enumerators, i.e., $\mathrm{Mr}$. Samweli Ole Milya and Mr. Nestory Dagharo for their tire less efforts during data collection in the field. Lastly, the authors offer their gratitude to Longido District officials for providing information and views on various aspects of livestock and agricultural production.

\section{Conflict Interest}

The other authors declare that they have no competing interest.

\section{Appendix}

Table 3. Profileof Respondents, Longido District, Northern Tanzania.

\begin{tabular}{lllll}
\hline Variable & Mountains & Hills & Lowlands & Total \\
\hline Household size & & & & \\
$2-5$ & 3 & 6 & 12 & 21 \\
$6-9$ & 22 & 27 & 28 & 77 \\
$10-15$ & 17 & 13 & 9 & 39 \\
$>16$ & 4 & 2 & 1 & 7.5 \\
\hline
\end{tabular}




\begin{tabular}{|c|c|c|c|c|c|}
\hline Variable & Mountains & Hills & Lowlands & Total & $\%$ \\
\hline Total & 46 & 48 & 50 & 144 & 100.0 \\
\hline \multicolumn{6}{|l|}{ Age category } \\
\hline $15-24$ (youths) & 5 & 1 & 0 & 6 & 4.2 \\
\hline 25-65 (adults) & 27 & 32 & 28 & 87 & 60.4 \\
\hline$>65$ (seniors) & 18 & 15 & 18 & 51 & 35.4 \\
\hline Total & 50 & 48 & 46 & 144 & 100.0 \\
\hline \multicolumn{6}{|c|}{ Highest level of education } \\
\hline None & 13 & 20 & 20 & 53 & 36.8 \\
\hline Primary & 29 & 13 & 22 & 64 & 44.4 \\
\hline Secondary & 7 & 12 & 2 & 21 & 14.6 \\
\hline Tertiary & 1 & 3 & 2 & 6 & 4.2 \\
\hline Total & 50 & 48 & 46 & 144 & 100.0 \\
\hline \multicolumn{6}{|c|}{ Main economic activity } \\
\hline Farming & 27 & 9 & 0 & 36 & 19.0 \\
\hline Pastoralism & 5 & 3 & 40 & 48 & 26.0 \\
\hline Agro-pastoralism & 18 & 36 & 6 & 60 & 32.0 \\
\hline Other & 13 & 17 & 14 & 44 & 23.0 \\
\hline Total & 63 & 65 & 60 & 188 & 100.0 \\
\hline \multicolumn{6}{|l|}{ Residential status } \\
\hline Settled & 40 & 43 & 39 & 122 & 84.7 \\
\hline Not settled & 10 & 5 & 7 & 22 & 15.3 \\
\hline Total & 50 & 48 & 46 & 144 & 100.0 \\
\hline \multicolumn{6}{|c|}{ Cultivated land size (ha) } \\
\hline $0.5-5.0$ & 60 & 38 & 3 & 101 & 70.1 \\
\hline $5.1-10.0$ & 16 & 17 & 2 & 35 & 24.3 \\
\hline $10.1-15.0$ & 4 & 2 & 0 & 6 & 4.2 \\
\hline$>15.1$ & 0 & 2 & 0 & 2 & 1.4 \\
\hline Total & 80 & 59 & 5 & 144 & 100.0 \\
\hline \multicolumn{6}{|l|}{ Type of livestock } \\
\hline Cattle & 734 & 1662 & 1757 & 4153 & 28.2 \\
\hline Sheep & 627 & 1968 & 2105 & 4700 & 32.0 \\
\hline Goat & 1201 & 2177 & 2474 & 5852 & 39.8 \\
\hline Total & 2562 & 5807 & 6336 & 14705 & 100.0 \\
\hline \multicolumn{6}{|c|}{ Income level per annum $\left(\mathrm{TZS}^{\prime} 000,000\right)$} \\
\hline$<0.1$ & 2 & 14 & 8 & 24 & 11.9 \\
\hline $0.11-0.50$ & 20 & 28 & 17 & 65 & 32.2 \\
\hline $0.51-1.0$ & 24 & 23 & 13 & 60 & 29.70 \\
\hline $1.1-5.0$ & 18 & 13 & 22 & 53 & 26.2 \\
\hline Total & 64 & 78 & 60 & 202 & 100.0 \\
\hline
\end{tabular}

Lands of Lower Eastern Kenya, Agriculture \& Food Security, $4(8) 1-13$.

\section{References}

[1] IUCN (Ed) 2013, Enhancing food security in pastoral areas through pastoralism and mobility. Proceedings of the 40 Committee of Food Security under the theme constraints to smallholder investments, bio fuels and food security Workshop, Rome, Italy, 7 October, 2013. 20pp.

[2] Krätli, S., Hülsebusch, C., Brooks, S. and Kaufmann, B. 2013, Pastoralism: A critical Asset for Food Security Under Global Climate Change. Animal Frontier. 3 (1):42-5.

[3] Christopher, W. 2016, Strengthening Food Security in Africa: A Case for Supporting Pastoralism in East Africa Report. Strengthening Contributions to Evidence-based Policy making, funded by the Canadian International Development Agency (CIDA).

[4] Nderumaki, V., Mkanda, F. X., Saria, J. 2016, Comparison of Food Insecurity among Agro-Pastoralists and Pastoralists Communities in Pastoral-Livelihood Zone of Longido District, Tanzania. Food Security, 4 (1)18-26.

[5] Omoyo, N. N., Wakhungu, J. and Oteng' I, S. 2015, Effects of Climate Variability on Maize Yield in the Arid and Semi Arid

[6] Ayanlade A., Odekunle, T. O., Orinmogunje, O. I., Adeoye, N. O. 2009, Inter-annual Climate Variability and Crop Yields Anomalies in the Middle Belt of Nigeria. Adv Nat Appl Sci. 3 (3):452-465.

[7] Conroy, A. 2005, Maasai Agriculture and Land Use Change.

[8] McCabe, J. T., Leslie, P. W. and De Luca, L. 2014, Adopting Cultivation to Remain Pastoralists: The Diversification of Maasai Livelihoods in Northern Tanzania. Hum Ecol Interdiscip J. 38 (3):321-334.

[9] Niamir-Fuller, F. 1994, The Resilience of Pastoral Herding in Sahelian Africa. In Linking Social and Ecological Systems: Management Practices and Social Mechanisms for Building Resilience. Cambridge University Press, Cambridge U.K.

[10] Parfitt, J. 1997, Questionnaire Design. In Flowerdew, E. And Martin, D. (Eds.). Methods in Human Geography; A Guide for Students Doing a Research Project, Longman, London.

[11] Valentine, G. 1997, Tell Me About Using Interviews as a Research Methodology. In: Flowerdew, E. And Martin, D. (eds.). Methods in Human Geography; a Guide for Students Doing a Research Project, Longman, London. 
[12] URT. 2013, Population and Housing Census 2012 and Population Distribution by Administrative Areas, Office of Chief Government Statistician President's Office, Finance, Economy and Development Planning.

[13] Sall, J. And Lehman, A. 1996, JMP Start Statistics; A Guide to Statistics and Data Analysis Using JMP and JMPIN Software. SAS. Institute Inc. International Thomson Publishing Company, New York.

[14] Selemani, I. S. 2014, Communal Grazing Lands Management and Challenges Underpinning Pastoral Mobility In Tanzania: A Review. Department of Animal Science and Production, Sokoine University of Agriculture. Livestock Research for Rural Development. (26)78.

[15] Plane, D. A. and Rogerson, P. A. 1994, The Geographical Analysis of Populations with Applications to Planning and Business. John Wiley and Sons Inc. New York.

[16] Infield, M. 1988, Attitudes of a Rural Community Towards Conservation and a Local Conservation Area in Natal, South Africa. Biol. Conserv. 45:21-46.

[17] Cohen, A. S., Bills, R., Cocquyt, C. Z., and Caljon, A. G. 1993, The Impact of Sediment Pollution on Biodiversity in Lake Tanganyika. Conservation Biology 7 (3):667-677.

[18] Shibia, M. G. 2010, Determinants of Attitudes and
Perceptions on Resource Use and Management of Marsabit National Reserve, Kenya. Human Ecology, 30 (1):55-6.

[19] Segnon, C. A., Achigan-Dako, E. G., Gaoue, G. O. and Ahanchédé, A. 2015, Farmer's Knowledge and Perception of Diversified Farming Systems in Sub- Humid and Semi- Arid Areas in Benin. Sustainability 7:6573-6592pp.

[20] O'Neil, D. 2011, Patterns of Subsistence: Pastoralism: In Classification of Cultures Based on the Sources and Techniques of Acquiring food and other Necessities.

[21] FEWSNET, 2015. East Africa Price Bulletin, Tanzania. 8pp.

[22] Moritz, M., Bebisse, L. C., Drent, A. K., Kari, S., Mouhaman, A. \& Scholte, P. 2013, Range land Governance in an Open System: Protecting Transhumance Corridors in The Far North Province of Cameroon. Pastoralism: Research, Policy and Practice, 3 (1)26.

[23] Mwamfupe, D. 2015, Persistence of Farmer-Herder Conflict in Tanzania, in International Journal of Scientific and Research Publications, (5)21-8.

[24] Garrett, H. 1968, The Tragedy of The Commons: The Population Problem has no Technical Solution; It Requires a Fundamental Extension in Morality. Science 162 (3859):12431248pp. 